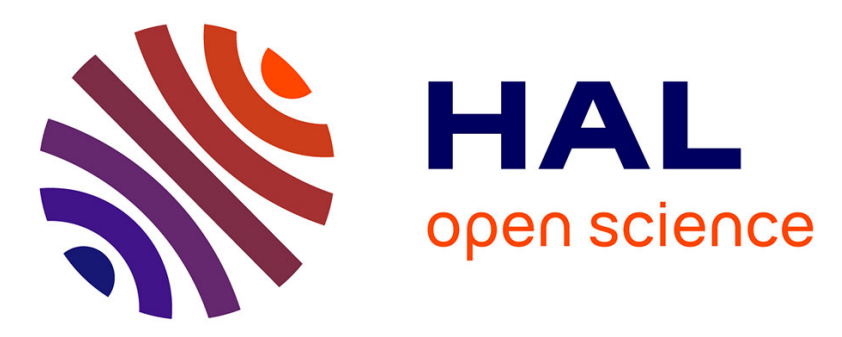

\title{
Testing the Validity of Simulated Strong Ground Motion from the Dynamic Rupture of a Finite Fault, by Using Empirical Equations
}

\author{
Hideo Aochi, John Douglas
}

\section{- To cite this version:}

Hideo Aochi, John Douglas. Testing the Validity of Simulated Strong Ground Motion from the Dynamic Rupture of a Finite Fault, by Using Empirical Equations. Bulletin of Earthquake Engineering, 2006, 4 (3), pp.211-229. 10.1007/s10518-006-0001-3 . hal-00557619

HAL Id: hal-00557619

https: / hal-brgm.archives-ouvertes.fr/hal-00557619

Submitted on 19 Jan 2011

HAL is a multi-disciplinary open access archive for the deposit and dissemination of scientific research documents, whether they are published or not. The documents may come from teaching and research institutions in France or abroad, or from public or private research centers.
L'archive ouverte pluridisciplinaire HAL, est destinée au dépôt et à la diffusion de documents scientifiques de niveau recherche, publiés ou non, émanant des établissements d'enseignement et de recherche français ou étrangers, des laboratoires publics ou privés. 


\title{
Testing the validity of simulated strong ground motion from the dynamic rupture of a finite fault, by using empirical equations
}

\author{
H. Aochi and J. Douglas, \\ ARN/RIS, BRGM, 3 avenue C. Guillemin, BP 6009, 45060 ORLEANS Cedex 2, France.
}

December 15, 2005

\begin{abstract}
This paper is concerned with testing the validity of the ground motions estimated by combining a boundary integral equation method to simulate dynamic rupture along finite faults with a finite difference method to compute the subsequent wave propagation. The validation exercise is conducted by comparing the calculated ground motions at about 100 hypothetical stations surrounding the pure strike-slip and pure reverse faults with those estimated by recent ground motion estimation equations derived by regression analysis of observed strong-motion data. The validity of the ground motions with respect to their amplitude, frequency content and duration is examined. It is found that the numerical simulation method adopted leads to ground motions that are mainly compatible with the magnitude and distance dependence modelled by empirical equations but that the choice of a low stress drop leads to ground motions that are smaller than generally observed. In addition, the scatter in the simulated ground motions, for which a laterally homogeneous crust and standard rock site were used, is of the same order as the scatter in observed motions therefore, close to the fault, variations in source propagation likely contribute a significant proportion of the scatter in observed motions in comparison with travel-path and site effects.
\end{abstract}

Running title: Testing the validity of simulated strong ground motion

Keywords: ground motion estimation equations, attenuation relations, boundary integral equation method, finite difference method, simulated ground motions, uncertainty

\section{Introduction}

Ground motions close to the fault are influenced directly by the rupture process. Hereafter, these ground motions are termed 'near-field' or 'near-source' ground motions in agreement with common engineering seismology terminology. Such rupture processes are very heterogeneous 
due to the existence of asperities and barriers, the fault geometry, fault segmentation and so forth. The rupture process can be simulated without any hypotheses on rupture area, amount of slip, rupture time, rupture directivity and slip-time function, but based on the mechanics controlled by an initial condition and some stress-slip constitutive law on the fault (dynamic rupture simulation). Compared to kinematic source models that are usually used for strong ground motion simulations, dynamic rupture simulations can propose possible rupture scenarios of different magnitudes under a given seismotectonic situation. This is a great advantage in evaluating the resultant strong ground motion even though it is still difficult to tune the model parameters.

The validity of simulations of seismic wave propagation from the dynamic rupture simulation has been only verified at low frequencies for near-field strong ground motion [Olsen et al., 1997, Peyrat et al., 2001, Aochi and Fukuyama, 2002, Aochi and Madariaga, 2003]. Olsen et al. [1997] and Peyrat et al. [2001] simulate the 1992 Landers, California, earthquake using a finite difference method (FDM) along a planar fault on which dynamic rupture spontaneously propagates following a certain stress-slip condition, and compare the synthetic and observed seismograms in the range $0.07-0.5 \mathrm{~Hz}$. Aochi and Fukuyama [2002] simulate the same earthquake using a boundary integral equation method (BIEM) for spontaneous rupture propagation along a complex fault geometry and use a discrete wavenumber method (DWM) [Bouchon, 1981] for consequent wave propagation in a similar frequency range $(0.05-0.3 \mathrm{~Hz})$. Aochi and Madariaga [2003] model the 1999 Izmit, Turkey, earthquake using a combination of BIEMs and FDMs for the entire process from spontaneous dynamic rupture propagation along a complex fault geometry to seismic wave propagation in the near field, and display the synthetic seismograms by applying a bandpass filter with cut-offs at 0.07 and $1 \mathrm{~Hz}$. It was difficult to precisely reproduce seismograms even at a frequency of $1 \mathrm{~Hz}$ in these simulations due to the existence of complexities in the source process, medium heterogeneity and site effects. Therefore, we need to identify for which range of frequencies our numerical scheme coupled with dynamic rupture is valid for strong ground motion prediction by comparing it to other common schemes that use kinematic or stochastic source models or, as in this study, empirical ground motion estimation equations (GMEEs) (commonly called attenuation relations).

Numerical stability and disturbance in FDM schemes have been well studied, while those in the BIEM during dynamic rupture simulation are rarely discussed. This is because macroscopic features such as rupture velocity, rupture direction and slip distribution are the focus of current seismological studies. In this article, we simulate seismic wave propagation using a FDM based on various rupture scenarios simulated by the BIEM used by Aochi et al. [2000], Aochi and Fukuyama [2002] and Aochi and Madariaga [2003]. In contrast to point comparisons that 
have been conducted for this method in the aforementioned articles, here we check its general validity by comparing the simulated ground motions in terms of their amplitude, frequency content and duration with motions predicted by GMEEs for a number of different strong-motion parameters. The strong-motion parameters chosen are: peak ground acceleration (PGA), peak ground velocity $(\mathrm{PGV})$, response spectral acceleration for 5\% damping at five periods (SA), Arias intensity (AI) [Arias, 1970] and relative significant duration (interval between 5-95\% of total Arias intensity) (RSD) [Trifunac and Brady, 1975]. It is important to compare the scatter within the simulations with that within observed data. Also, to check the internal consistency of the simulated ground motions, we compare the correlations between these ground-motion parameters using the simulated data with those observed within real data.

\section{Simulation method}

In this section we discuss the simulation methods used in this study for dynamic rupture of the fault and for the subsequent wave propagation. Table 1 shows a list of model parameters in the lead author's previous simulations with, for comparison, those used in this study.

\subsection{Dynamic rupture simulation using the BIEM}

The BIEM is useful for simulations of the dynamic rupture propagation on faults, because of its accuracy in stress-velocity evaluation around the crack tip and its flexibility with respect to fault geometry thanks to the mathematical formulations beginning with the representative theorem of the elastic medium. All previous simulations of dynamic rupture propagation listed in Table 1 were computed using a 3D BIEM [Aochi et al., 2000] formulated in an infinite uniform elastic medium. The discretization within BIEMs is not a discrete sampling procedure such as in FDMs, but a mathematically strict formulation in which the slip velocity is constant on a single squared grid during a single time step. We then carry out the convolutions (once in time, twice in space) for every concerned point in the medium, so that calculation becomes more expensive for larger models. As seen in Table 1, the currently available computer resources (CPU time) limit the BIEM resolution to, at best, a size of spatial cell on the earthquake fault of $256 \mathrm{~m}$ for events of magnitudes between 5.9 and 7.6.

The rupture process in all these simulations like many others' studies is controlled by the form of slip-weakening friction law [Ida, 1972, Palmer and Rice, 1973], which describes the evolution of fault strength during fault slip (a more detailed explanation is given in the Appendix). This law contains a scale parameter $D_{c}$ called the slip-weakening distance, which was found to be of the order of $10 \mathrm{~cm}$ during the 1995 Kobe and the 1992 Landers earthquakes 
[Ide and Takeo, 1997, Olsen et al., 1997]. From the numerical point-of-view, this $D_{c}$ value limits the simulation resolution together with the cell size on the fault, that is, a smaller $D_{c}$ requires a 'numerically' smaller cell size to preserve accuracy.

In modelling real earthquakes in previous studies, the results of the BIEM were presented at $1 \mathrm{~Hz}$, that is, in snapshots of every $1 \mathrm{~s}$, because the synthetic seismograms are compared upto $1 \mathrm{~Hz}$ with the observations, like in many seismic inversion analyses of finite source models. With respect to purely numerical issues, we should be able to model higher frequencies (more detail) in the rupture process. This is an important objective of this study.

[Table 1 about here.]

\subsection{Wave propagation simulations}

In previous studies (Table 1), two methods (DWM and FDM) were used for simulating seismic wave propagation from faults. The advantage of the DWM is numerical accuracy over a wide range of frequencies, however the medium structure is limited to stratified layers and it is time consuming to calculate motions at many points. On the other hand, although FDMs are not better with respect to numerical accuracy, they have the principal merits of being able to treat any heterogeneous medium and in allowing volumetric visualization of wave propagation without increasing the number of numerical calculations. Added to these benefits, rapid computer developments since the 1990s have improved the various FDMs and they now allow larger and larger calculations for practical applications. Thus in this study we use a FDM for calculating the synthetic seismograms.

Our FDM, the same as in Aochi and Madariaga [2003] and Aochi and Olsen [2004], is based on the standard formulation of the 4th-order staggered grid in a 3D isotropic elastic medium [Olsen, 1994, Graves, 1996]. We follow the same treatments of free surface and attenuation as Graves [1996], the same interface between BIEM and FDM as Olsen et al. [1999] and the same absorbing boundary condition as Collino and Tsogka [2001]. The numerical stability of the FDM is easy to check for a unit point source with a known frequency content. Our dynamic source model has complex frequency content, which may include both physical signals and numerical noise, therefore there are no analytical equations available. Unlike a point source model, our rupture area evolves spatially with time and the slip history varies along the fault so that it is almost impossible to analytically estimate the frequency content of the radiated seismic wave at the source. This is why we statistically compare near-field synthetic seismograms with empirical relations. This procedure will allow us to distinguish different effects at various frequencies due to the source mechanism, the path or simply numerical disturbance. 


\section{Scenarios simulated}

In this article we consider a blind fault system consisting of a single planar fault with different fault parameters (strike, dip and rake) embedded in an elastic medium. Figure 1 shows all the configurations of the fault orientation and the location of hypothetical seismic stations, where the simulated ground motions are examined. Table 2 gives details of the fault parameters for each simulated scenario. The reason why the same fault dimension have different magnitudes (Scenarios 4, 5 and 6) is the effect of dynamic rupture due to differing slip directions. The depth of the top of the fault is fixed at $1 \mathrm{~km}$ and a hypocenter location is assumed at the bottom corner of each fault. This allows us to clearly study the asymmetric effect of dynamic rupture propagation. Our simulations consists of two parts: dynamic rupture progress using the BIEM and seismic wave propagation using the FDM. Below we show some examples of simulated wave propagation and discuss the simulated ground motions, which are our interest in this paper. Details of rupture simulation are given in the Appendix.

[Figure 1 about here.]

[Table 2 about here.]

Synthetic seismograms are calculated, based on the seven earthquake simulations, at imaginary stations located every $5 \mathrm{~km}$ on the ground surface (Figure 1). A simple 1D crustal model (Table 3) is assumed in order to avoid any unnecessary numerical disturbance due to the complexity in wave propagation. Under our available computational environment (Xeon $3.06 \mathrm{GHz} \times 24$ at maximum), we can afford to calculate 32 million grid points (corresponding to $400 \times 400 \times 200$ ) including a finite source model. We simulate ground motions in two regions for one rupture simulation by shifting the calculating region as shown in Figure 1, simply because the total area is too large to handle in one run. Through our preliminary simulations [Aochi and Douglas, 2005], it is found that FDM grid size should be much smaller than BIEM grid size, so that we choose a FDM grid size of $100 \mathrm{~m}$ in this study (time step is set to be $0.005 \mathrm{~s}$ ). The BIEM-FDM interface at $10 \mathrm{~Hz}$ is also found to be sufficient for discussing our target frequency upto $10 \mathrm{~Hz}$, which may be generated in our dynamic rupture simulation, but in reality the given FDM grid size strictly limits the reliable frequency upto a few Hz. We prefer not to apply any filtering to the calculated seismograms after testing some low-pass filters to confirm no significant high frequency oscillations, although seismologists usually focus only on a limited frequency range. This is because one of our main purposes is to know the practical limitation of the BIEM-FDM hybrid method and because the raw calculation results are required for further simulations of site effects. 
[Table 3 about here.]

Figure 2 shows two examples of the numerical simulations. The first example (scenario 4) shows the typical features of this sort of strike-slip fault: symmetry with respect to the fault trace, strong directivity in the northern direction and small amplitude of the vertical component $(z)$. On the other hand, the second example (scenario 5) demonstrates a typical feature of reverse faulting: the appearance of a large vertical component on the hanging wall. Figure 3 shows simulated velocity time-histories for this scenario, again showing strong directivity effects close to the source.

[Figure 2 about here.]

[Figure 3 about here.]

\section{Validation of the simulation method}

It is important to validate the simulated motions with respect to their characteristics in terms of amplitude, frequency content and duration so that they can be used with confidence for nonlinear engineering analysis that requires time-histories that are realistic with respect to these three characteristics. Anderson [2004] proposes a quantitative measure of the goodness-of-fit between synthetic and observed accelerograms using ten different criteria that measure different aspects of the motions. The ground motion simulations discussed here are for simplified rupture scenarios and ideally located stations therefore it is impossible to compare the simulations directly with observations like has been done in the past [e.g. Silva et al., 1999, Aochi and Madariaga, 2003, Douglas et al., 2004]. Therefore in order to validate the simulations they are compared with predictions from ground-motion models derived from regression analysis of observed data [e.g. Douglas, 2003]. Since here the simulated ground motions are not compared with other time-histories but only with estimated strong-motion parameters it is not possible to use all the ten measurements Anderson [2004] proposes. However, a similarly broad range of parameters is chosen to measure the match between different aspects of simulated and observed motions. An optimum evaluation requiring limited computation would investigate a series of strong-motion parameters that are poorly correlated (orthogonal), and hence measure different aspects of ground motions, but which are ultimately useful as input to fragility curves for seismic risk assessment. The estimates from the GMEEs are assumed to model the expected average ground motions for a given magnitude, distance and mechanism and the expected scatter in ground motions is modelled by the associated standard deviation of the equations used. Table 4 gives details of the equations selected. 
[Table 4 about here.]

All the equations selected use moment magnitude $\left(M_{w}\right)$ therefore no magnitude conversion was required. Distances to the surface projection of the fault and to the rupture plane of the fault were calculated for all the stations and the seven scenarios. All motions were computed for rock conditions since no near-surface low-velocity layers were included in the simulation. To obtain the empirical parameters, we directly analyse the raw synthetic seismograms without applying any filtering.

In this article, residuals, $\epsilon$, are defined as: $\epsilon=\log _{10}\left(y_{\mathrm{emp}}\right)-\log _{10}\left(y_{\mathrm{syn}}\right)=\log _{10}\left(y_{\mathrm{emp}} / y_{\mathrm{syn}}\right)$, where $y_{\mathrm{emp}}$ is the strong-motion parameter predicted using the empirical equations and $y_{\mathrm{syn}}$ is the strong-motion parameter from the synthetic accelerogram.

\subsection{Residuals}

Synthetic accelerograms are rarely shown for such a model when this type of FDM is used. However, PGA is one of the parameters most of interest to engineering seismologists. Figure 4 shows the residuals between the empirical estimates and the simulations for horizontal PGA with respect to scenario and distance. We note again that no filtering process is applied to the calculated accelerograms. Thus we need to careful consider the frequency range for which the simulations are valid.

[Figure 4 about here.]

[Table 5 about here.]

Table 5 gives the computed mean bias and standard deviations for PGA. From Figure 4 it can be seen that the residuals are reasonably constant with scenario and distance and hence the dependence on magnitude, distance and mechanism of the simulations is similar to that modelled by the GMEE. However, the absolute value of the PGA is significantly underestimated (a factor of about four) by the simulations. Part of this underestimation is due to the lack of shallow low velocity layers within the crustal model, which are common even at stations on rock and which amplify short-period motions [Boore and Joyner, 1997]. The main reason for this underestimation originates from our choice of fault rupture parameters, as explained in detail in Section 4.2.

PGV is the mostly favoured parameter to display FDM simulations, because the method is formulated in terms of stress-velocity. Figure 5 shows the residuals between the empirical estimates and the simulations for horizontal PGV with respect to scenario and distance and Table 5 gives the computed mean bias and standard deviations for PGV. The residuals again 
show no dependence on scenario or distance thereby showing that the dependence on magnitude, distance and mechanism within the simulated ground motions is similar to that within the GMEE and consequently similar to that observed in reality. However, again the absolute value of the ground motion is underestimated (see Section 4.2).

Similar results are found for SA and AI (see Table 5). The residuals of AI show a dependence with distance (see Figure 6), which is thought to be due to strong directivity effects within the simulations that are not modelled by the selected GMEE.

[Figure 5 about here.]

[Figure 6 about here.]

Figure 7 shows the residuals between the empirical estimates and the simulations for horizontal RSD with respect to scenario and distance. Table 5 gives the computed mean bias and standard deviations for RSD. Table 5 and Figure 7 show that the relative significant durations of the simulations closely match those predicted by the empirical equation. This is in contrast to the amplitude strong-motion parameters discussed above; relative significant duration is not strongly affected by the choice of fault rupture parameters and hence the predictions from the simulations are good. This finding that the duration of strong ground motions can be well simulated is important because duration effects are becoming increasingly discussed with respect to their importance for evaluating how damaging ground motions are to structures [e.g. Bommer et al., 2004, Chai, 2005].

[Figure 7 about here.]

\subsection{Underestimated absolute values in simulations}

As shown in the previous section, our simulations give relatively small average values with respect to those expected for all parameters, except RSD. The reason for this underestimation is the choice of fault rupture parameters given in Table 8 in the Appendix. Stress drop, defined by the difference of initial shear and residual stresses, is $3 \mathrm{MPa}$ (30 bar) in all the simulations. This value is quite reasonable for interplate earthquakes while this should be larger, about $10 \mathrm{MPa}$ (100 bar), for intraplate earthquakes [Kanamori and Anderson, 1975]. The geometrical configuration of our simulation (near-field stations) is often seen for intraplate earthquakes, and the GMEEs chosen were derived from such data. It is found that the average levels of ground-motion parameters are well estimated when a value of $10 \mathrm{MPa}(100 \mathrm{bar})$ is used for the stress drop [Aochi and Douglas, 2005]. Even when a higher stress drop is used, the standard deviations obtained remain between 0.2 and 0.3 for most parameters. Hence, we believe that 
this scatter is significant as an universal feature of such numerical simulations, therefore we discuss this aspect in the next section.

\subsection{Scatter in simulations}

Table 5 shows that all the computed standard deviations of the residuals between the synthetics and the empirical equations are similar to those computed between observed motions and the empirical equations. By adjusting the fault rupture parameters we are able to vary the absolute values of the computed parameters, however the scatter in simulations always exists with a standard deviation of about $0.2-0.3$. When we look carefully at synthetic seismograms, large amplitudes are observed in the forward direction of rupture propagation, as reported in many studies [e.g. Somerville et al., 1997]. In contrast, it should be noted that amplitudes are much smaller in the backward direction. Although this is not so often stated, these small amplitudes cause some of the large residuals observed.

Since the effect of a heterogeneous crust and variations in local site conditions are not included within the simulations, this finding of similar scatter to observational studies suggests that a larger proportion of scatter in real near-source ground motions is due to source effects than to travel path or local site effects. If variations in site effects are superimposed onto the simulated bedrock motions then the scatter in the simulations will increase.

\subsection{Correlations between strong-motion parameters}

Another requirement for simulated ground motions is that the correlations between strongmotion parameters computed from the synthetics are similar to those observed in real strongmotion records. This is important because if the simulated ground motions are used as input to, for example, a nonlinear analysis of a structure or a nonlinear site response analysis then in order to obtain results consist with what could occur in practice correlations between the amplitude, frequency and duration characteristics of the synthetics (characterised by the strong-motion parameters) must be realistic.

The data used to derive the equations in Ambraseys et al. [2005a], which consists of 595 individually corrected triaxial strong-motion records, was used to compute correlation coefficients between all the strong-motion parameters investigated here, see Table 7. Comparing Table 6 (from the simulated data) and 7 shows that similar correlations are observed within the simulated data and within the observed data, e.g. weak negative correlation between duration and amplitude measures and strong positive correlations between peak ground acceleration and short period spectral accelerations. Similar results were obtained for vertical components.

[Table 6 about here.] 
[Table 7 about here.]

\section{Conclusions}

In this article, we use seven dynamic rupture scenarios, simulated using a BIEM, of a finite fault as input to a FDM to simulate the generated ground motions at about one hundred near-source locations. Next nine strong-motion parameters that characterise the amplitude, frequency and duration content of these motions are calculated for all records. Finally, the residuals of these parameters with respect to estimates of the parameters given by recent GMEEs for the chosen parameters are computed.

It is found that the strong-motion parameters from the simulations scale similarly with respect to magnitude, source-to-site distance and mechanism as observed data, however, the choice of a low stress drop in the BIEM simulations leads to simulated ground motions that are, in general, lower than those observed in reality. Relative significant durations of the simulated motions match closely those estimated by the GMEEs at all distances and for all scenarios. It is found that the scatter in the simulated ground motions, for which a laterally homogeneous crust and standard rock site were used, is of the same order as the scatter in observed motions. This suggests that in the near-source region, variations in source propagation contribute a significant proportion of the scatter in observed motions in comparison with travel-path and site effects. This scatter is not sensitive to the chosen fault rupture parameters, unlike the absolute values of the ground-motion parameters implying that the variations in near-field ground motion originates from details of the rupture process on a finite fault.

In conclusion, the simulation method tested here (the boundary integral equation method combined with a finite difference scheme) results in statistically compatible strong ground motion with similar magnitude, distance and mechanism dependence to that observed in real data. However, fault rupture parameters should be carefully chosen in future studies.

\section{Acknowledgements}

This study was funded by SIS3D and RISQSIS (two internal BRGM research projects). Mr J. Hancock provided some useful advice on equations for the estimation of duration and also reviewed the first version of the article, Ms F. O. Strasser gave us some useful suggestions on observed periodic oscillations and Dr J.A. Prieto-Salazar for his suggestions on different aspects of this work. We thank two anonymous reviewers for their valuable comments that improved the article. 


\section{References}

N. A. Abrahamson and W. J. Silva. Empirical ground motion models. Technical report, 1996. Report to Brookhaven National Laboratory. Cited in Stewart et al. [2001].

N. N. Ambraseys, J. Douglas, S. K. Sarma, and P. M. Smit. Equations for the estimation of strong ground motions from shallow crustal earthquakes using data from Europe and the Middle East: Horizontal peak ground acceleration and spectral acceleration. Bulletin of Earthquake Engineering, 3(1):1-53, 2005a.

N. N. Ambraseys, J. Douglas, S. K. Sarma, and P. M. Smit. Equations for the estimation of strong ground motions from shallow crustal earthquakes using data from Europe and the Middle East: Vertical peak ground acceleration and spectral acceleration. Bulletin of Earthquake Engineering, 3(1):55-73, 2005b.

J. G. Anderson. Quantitative measure of the goodness-of-fit of synthetic seismograms. In Proceedings of Thirteenth World Conference on Earthquake Engineering, 2004. Paper no. 243.

H. Aochi and J. Douglas. Testing the validity of simulated strong ground motion from the dynamic rupture of a fault system, by using empirical equations. Technical Report BRGM/RP53800-FR, BRGM, Orléans, France, Mar. 2005.

H. Aochi and E. Fukuyama. Three-dimensional nonplanar simulation of the 1992 Landers earthquake. Journal of Geophysical Research, 107(2):doi:10.1029/2001JB000061, Feb 2002.

H. Aochi, E. Fukuyama, and R. Madariaga. Constraints of fault constitutive parameters inferred from non-planar fault modeling. Geochemistry, Geophysics, Geosystems, 4(2): doi:10.1029/2001GC000207, 2003.

H. Aochi, E. Fukuyama, and M. Matsu'ura. Spontaneous rupture propagation on a non-planar fault in 3-D elastic medium. Pure and Applied Geophysics, 157(11-12):2003-2027, Nov-Dec 2000.

H. Aochi and S. Ide. Numerical study on multi-scaling earthquake rupture. Geophysical Research Letters, 31:L02606, doi:10.1029/2003GL018708, 2004.

H. Aochi and R. Madariaga. The 1999 Izmit, Turkey, earthquake: Nonplanar fault structure, dynamic rupture process, and strong ground motion. Bulletin of the Seismological Society of America, 93(3):1249-1266, Jun 2003. 
H. Aochi and K. B. Olsen. On the effects of non-planar geometry for blind thrust faults on strong ground motion. Pure and Applied Geophysics, 168(11-12):1-15, Nov-Dec 2004.

A. Arias. A measure of earthquake intensity. In R.J. Hansen, editor, Seismic Design for Nuclear Power Plants, pages 438-483. The M.I.T. Press, 1970.

J. J. Bommer, G. Magenes, J. Hancock, and P. Penazzo. The influence of strong-motion duration on the seismic response of masonry structures. Bulletin of Earthquake Engineering, 2(1):1-26, Jan 2004.

D. M. Boore and W. B. Joyner. Site amplifications for generic rock sites. Bulletin of the Seismological Society of America, 87(2):327-341, Apr 1997.

M. Bouchon. A simple method to calculate Green's functions for elastic layered media. Bulletin of the Seismological Society of America, 71(4):959-971, Aug 1981.

K. W. Campbell. Empirical near-source attenuation relationships for horizontal and vertical components of peak ground acceleration, peak ground velocity, and pseudo-absolute acceleration response spectra. Seismological Research Letters, 68(1):154-179, Jan/Feb 1997.

K. W. Campbell. Erratum: Empirical near-source attenuation relationships for horizontal and vertical components of peak ground acceleration, peak ground velocity, and pseudo-absolute acceleration response spectra. Seismological Research Letters, 71(3):352-354, May/Jun 2000.

K. W. Campbell. Erratum: Empirical near-source attenuation relationships for horizontal and vertical components of peak ground acceleration, peak ground velocity, and pseudo-absolute acceleration response spectra. Seismological Research Letters, 72(4):474, Jul/Aug 2001.

Y. H. Chai. Incorporating low-cycle fatigue model into duration-dependent inelastic design spectra. Earthquake Engineering and Structural Dynamics, 34:83-96, 2005.

F. Collino and C. Tsogka. Application of the perfectly matched absorbing layer model to the linear elastodynamic problem in anisotropic heterogeneous media. Geophysics, 66(1): 2940-307, Feb 2001.

J. Douglas. Earthquake ground motion estimation using strong-motion records: A review of equations for the estimation of peak ground acceleration and response spectral ordinates. Earth-Science Reviews, 61(1-2):43-104, 2003.

J. Douglas, P. Suhadolc, and G. Costa. On the incorporation of the effect of crustal structure into empirical strong ground motion estimation. Bulletin of Earthquake Engineering, 2(1): 75-99, 2004. 
R. W. J. Graves. Simulating seismic wave propagation in 3D elastic media using staggeredgrid finite differences. Bulletin of the Seismological Society of America, 86(4):1091-1106, Aug 1996.

Y. Ida. Cohesive force across the tip of a longitudinal-shear crack and griffith's specific surface energy. Journal of Geophysical Research, 77:3796-3805, 1972.

S. Ide and M. Takeo. Determination of constitutive relations of fault slip based on seismic wave analysis,. Journal of Geophysical Research, 102:27379-27391, 1997.

H. Kanamori and D. L. Anderson. Theoretical basis of some empirical relations in seismology. Bulletin of the Seismological Society of America, 65(5):1073-1095, Oct 1975.

K. B. Olsen. Simulation of three-dimensional wave propagation in the Salt Lake Basin. $\mathrm{PhD}$ thesis, University of Utah, 1994.

K. B. Olsen, E. Fukuyama, H. Aochi, and R. Madariaga. Hybrid modeling of curved fault radiation in a 3D heterogeneous medium. In M. Matsu'ura, K. Nakajima, and P. Mora, editors, 2nd ACES Workshop Proceedings, pages 343-349, 1999.

K. B. Olsen, R. Madariaga, and R. J. Archuleta. Three-dimensional dynamic simulation of the 1992 Landers earthquakes. Science, 278(5339):834-838, Oct 1997.

A. C. Palmer and J. R. Rice. The growth of slip surfaces in the progressive failure of overconsolidated clay. Proc. R. Soc. London, Ser. A, 332:527-548, 1973.

S. Peyrat, K. Olsen, and R. Madariaga. Dynamic modeling of the 1992 Landers earthquake. Journal of Geophysical Research, 106(11):26467-26482, Nov 2001.

W. Silva, N. Gregor, and B. Darragh. Near fault ground motions. Technical report, Pacific Engineering and Analysis, El Cerrito, USA, Sep 1999. PG\&E PEER - Task 5.A.

P. G. Somerville, N. F. Smith, R. W. Graves, and N. A. Abrahamson. Modification of empirical strong ground motion attenuation relations to include the amplitude and duration effects of rupture directivity. Seismological Research Letters, 68(1):199-222, 1997.

J. P. Stewart, S.-J. Chiou, J. D. Bray, R. W. Graves, P. G. Somerville, and N. A. Abrahamson. Ground motion evaluation procedures for performance-based design. PEER Report 2001/09, Pacific Earthquake Engineering Research Center, College of Engineering, University of California, Berkeley, USA, Sep 2001. 
T. Travasarou, J. D. Bray, and N. A. Abrahamson. Empirical attenuation relationship for Arias intensity. Earthquake Engineering and Structural Dynamics, 32:1133-1155, 2003. DOI: 10.1002/eqe. 270 .

M. D. Trifunac and A. G. Brady. A study on the duration of strong earthquake ground motion. Bulletin of the Seismological Society of America, 65(3):581-626, Jun 1975.

\section{Appendix}

In this section, we detail the dynamic rupture simulations made using the BIEM. The slipweakening law used in dynamic rupture simulations is simply written as:

$$
\tau(\Delta u)=\tau_{r}+\left(\tau_{p}-\tau_{r}\right)\left(1-\frac{\Delta u}{D_{c}}\right) H\left(1-\frac{\Delta u}{D_{c}}\right),
$$

where $\tau_{p}$ and $\tau_{r}$ are peak and residual strength, $D_{c}$ is again called the slip-weakening distance, and $H(\cdot)$ is the Heaviside function. In all the simulations of earthquakes with magnitudes about 7, the two important factors $\left(\tau_{p}-\tau_{r}\right)$ and $D_{c}$ are taken to be roughly $5 \mathrm{MPa}$ and $12.5 \mathrm{~cm}$, respectively, so that the resultant slip time functions on faults are similar and reasonable with respect to various seismological inversion results. The parameters used in this study are summarised in Table 8, which are reasonable compared to those used in previous studies. We begin the simulations in the manner of Aochi and Ide [2004] who introduced a self-similar rupture growth without any finite initial crack. This procedure is conducted in the $16 \times 16$ grids surrounding the hypocenter.

One typical example (Simulation 4) is shown in Figure 8. In this example the rupture begins at the bottom corner of the fault plane and progresses in a diagonal direction. As we do not assume any heterogeneity on the fault, the rupture process is rather uniform and smooth. The variety in fault dimension and orientation and in propagation process within the simulations makes them suitable for the statistical tests conducted in this paper. Note that the BIEM simulations are made in a finite, homogeneous elastic medium, and then these results are used as input in the semi-finite, heterogeneous medium of the FDM simulations.

[Table 8 about here.]

[Figure 8 about here.] 


\section{List of Figures}

1 Map of fault orientations and the location of points where the ground motions are examined. Broken lines show the real model area simulated each time using the FDM, stars represent hypocenters assumed in each simulation and dots are the stations. Also see Table 2. . . . . . . . . . . . . . . . . . . . . . . . 16

2 Snapshots of three components of simulated ground motion velocity for Scenarios 4 (left) and 5 (right). . . . . . . . . . . . . . . . . . . 17

3 Velocity time-histories (NS component) simulated for Scenario 5. The box represents the surface projection of the rupture and the star shows the location of the epicentre. . . . . . . . . . . . . . . . . . . .

4 Residuals between the empirical estimates and the simulations for horizontal PGA with respect to scenario and distance to the surface projection of rupture.

5 Residuals between the empirical estimates and the simulations for horizontal PGV with respect to scenario and distance to the seismogenic rupture. . . . . . 20

6 Residuals between the empirical estimates and the simulations for horizontal AI with respect to scenario and distance to the rupture. . . . . . . . . . . . . . . . 21

7 Residuals between the empirical estimates and the simulations for horizontal RSD with respect to scenario and distance to the rupture. . . . . . . . . . . . . 22

8 Snapshots of rupture propagation simulated with BIEM (Simulation 4). . . . . 23 


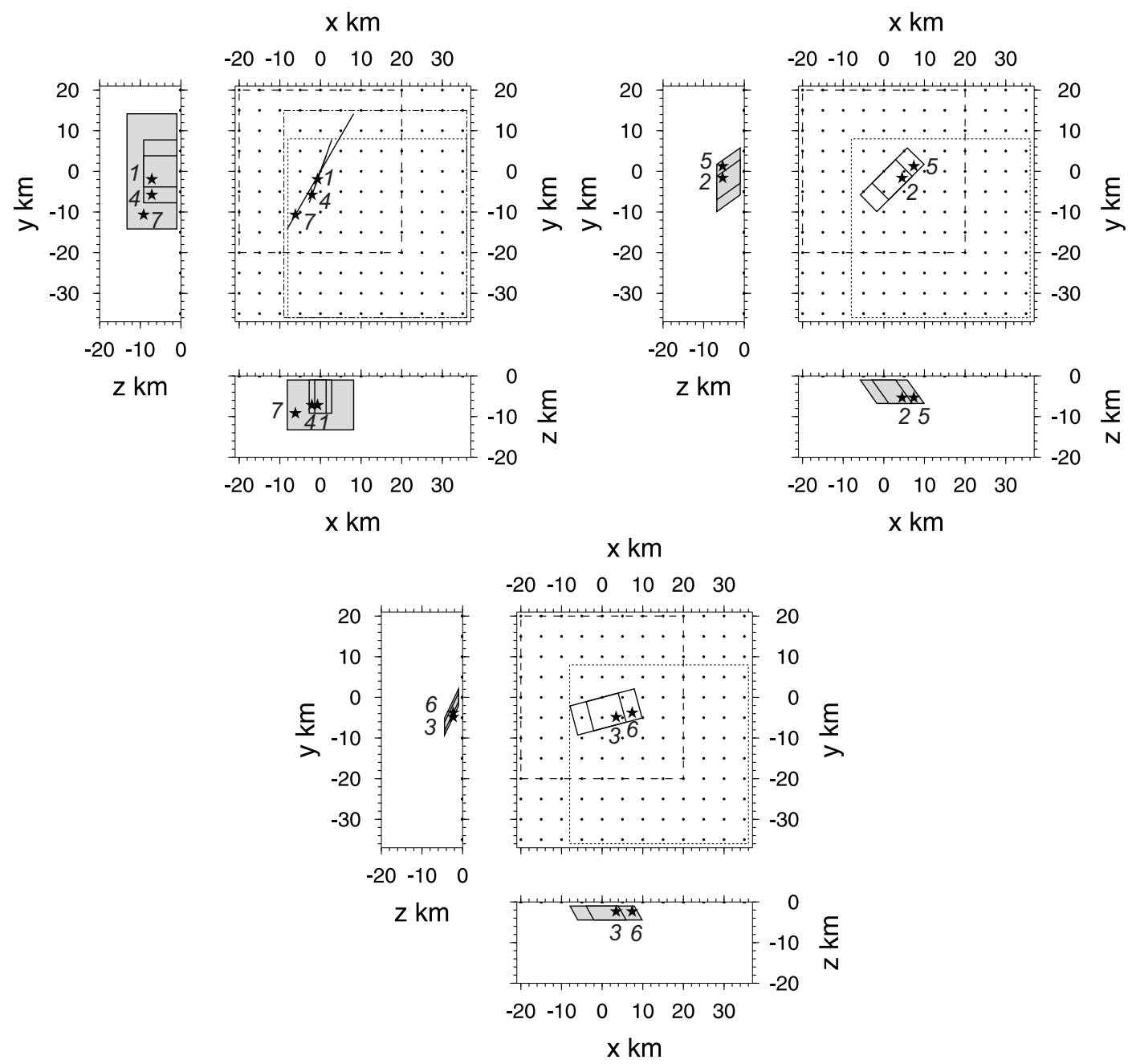

Figure 1: Map of fault orientations and the location of points where the ground motions are examined. Broken lines show the real model area simulated each time using the FDM, stars represent hypocenters assumed in each simulation and dots are the stations. Also see Table 2. 


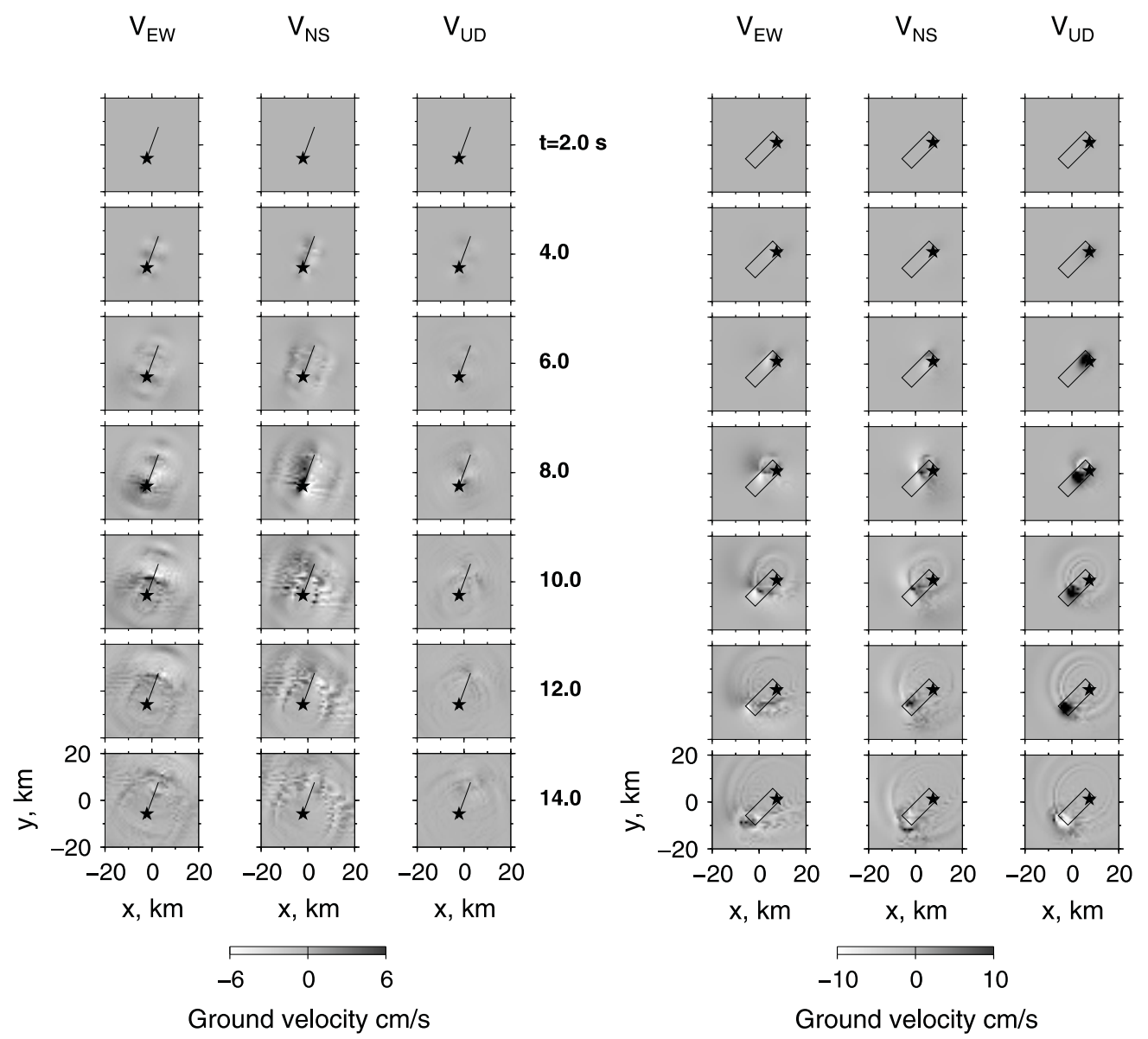

Figure 2: Snapshots of three components of simulated ground motion velocity for Scenarios 4 (left) and 5 (right). 


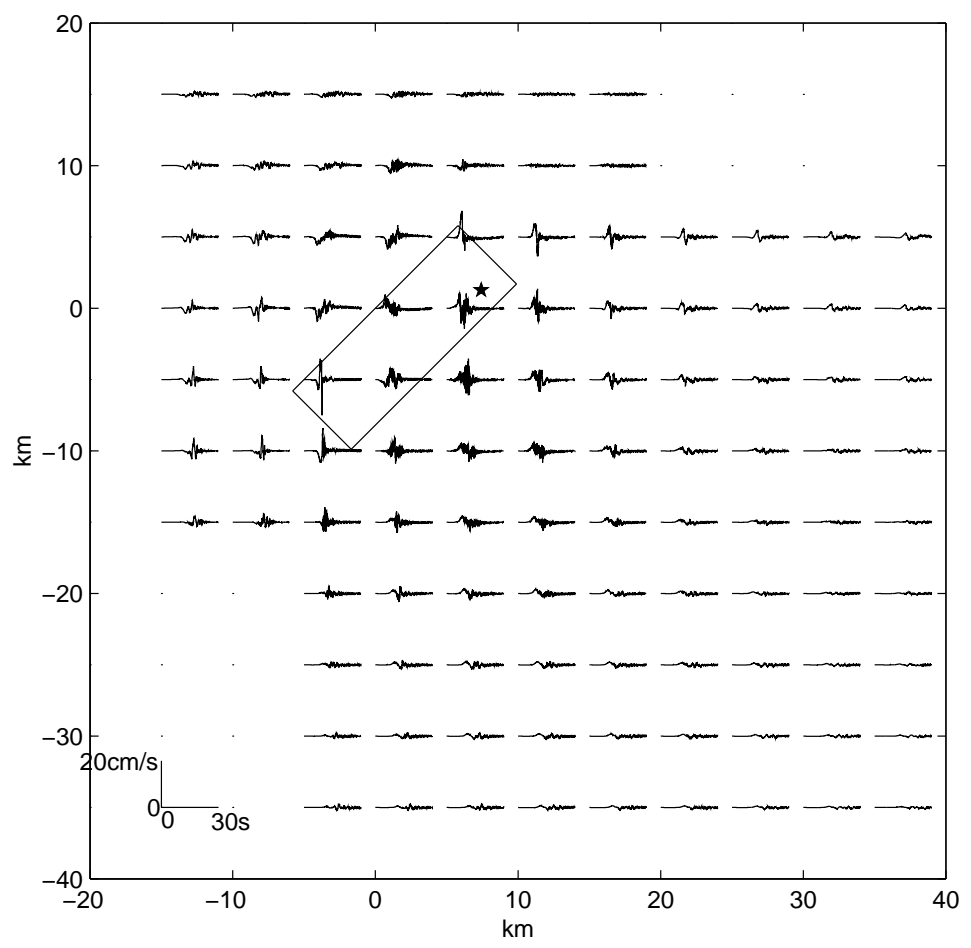

Figure 3: Velocity time-histories (NS component) simulated for Scenario 5. The box represents the surface projection of the rupture and the star shows the location of the epicentre. 

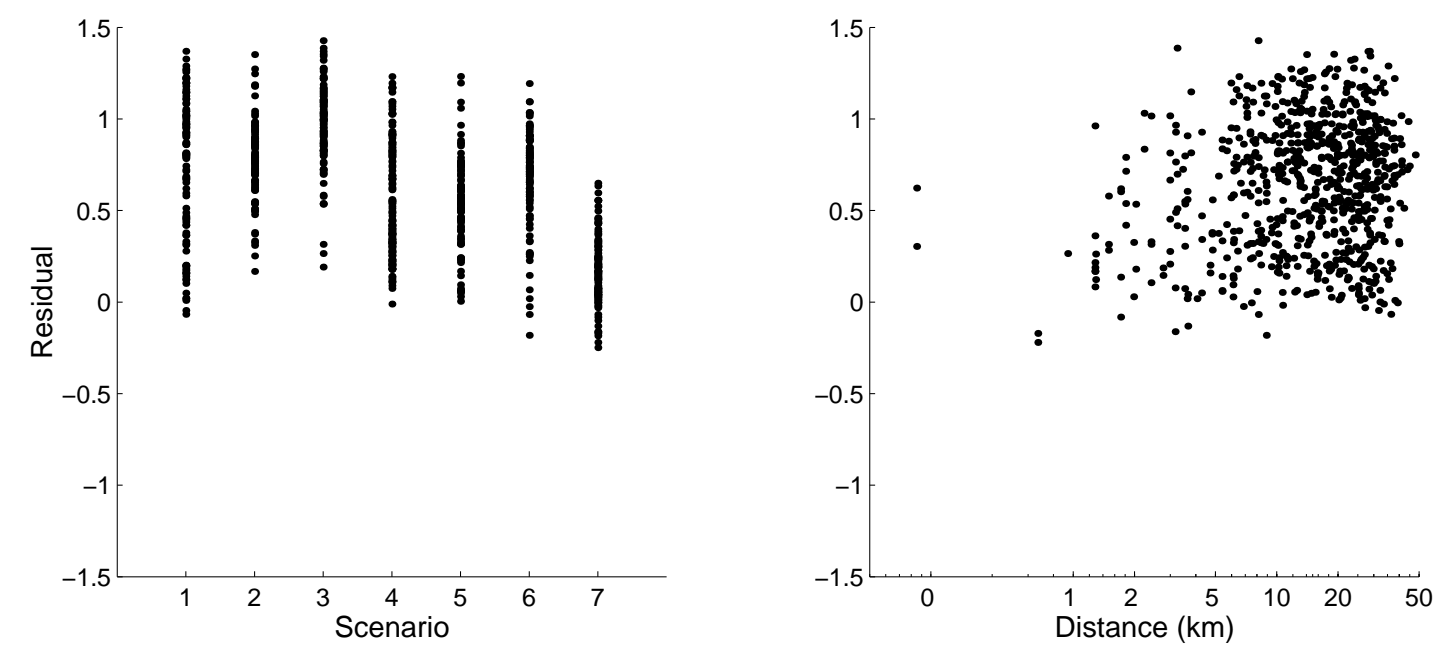

Figure 4: Residuals between the empirical estimates and the simulations for horizontal PGA with respect to scenario and distance to the surface projection of rupture. 

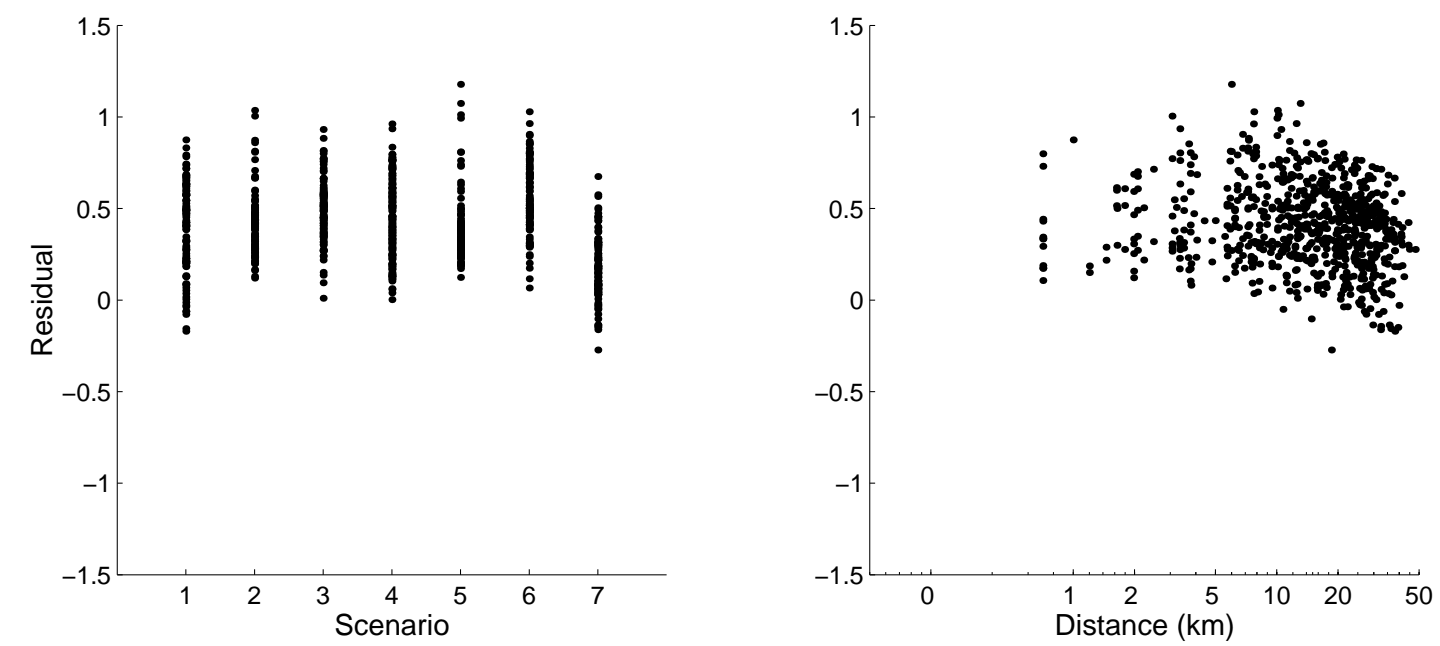

Figure 5: Residuals between the empirical estimates and the simulations for horizontal PGV with respect to scenario and distance to the seismogenic rupture. 

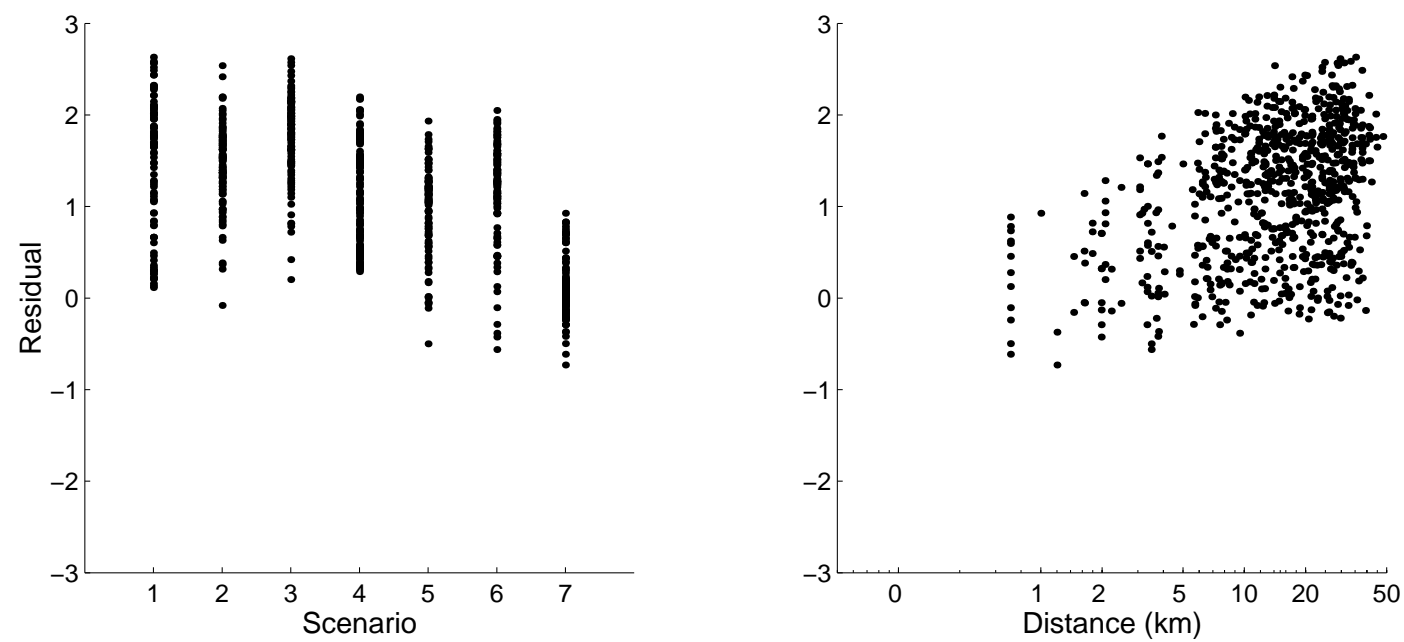

Figure 6: Residuals between the empirical estimates and the simulations for horizontal AI with respect to scenario and distance to the rupture. 

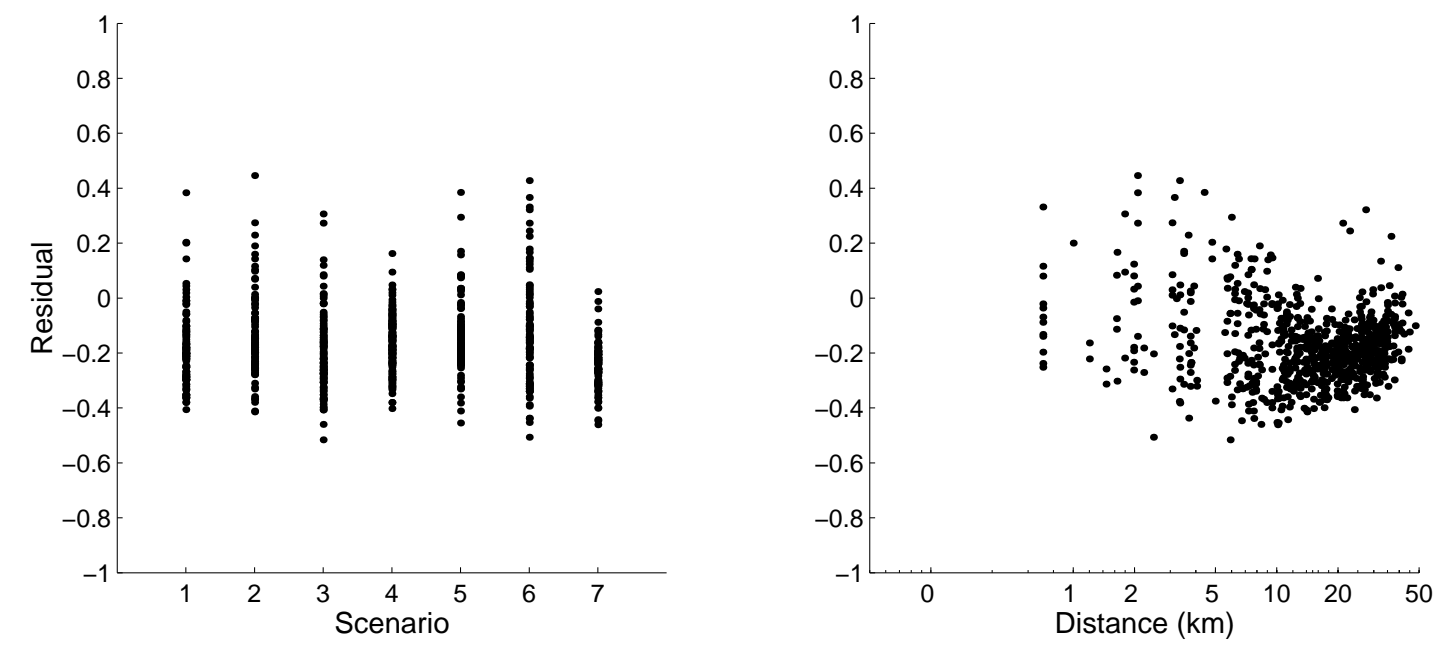

Figure 7: Residuals between the empirical estimates and the simulations for horizontal RSD with respect to scenario and distance to the rupture. 


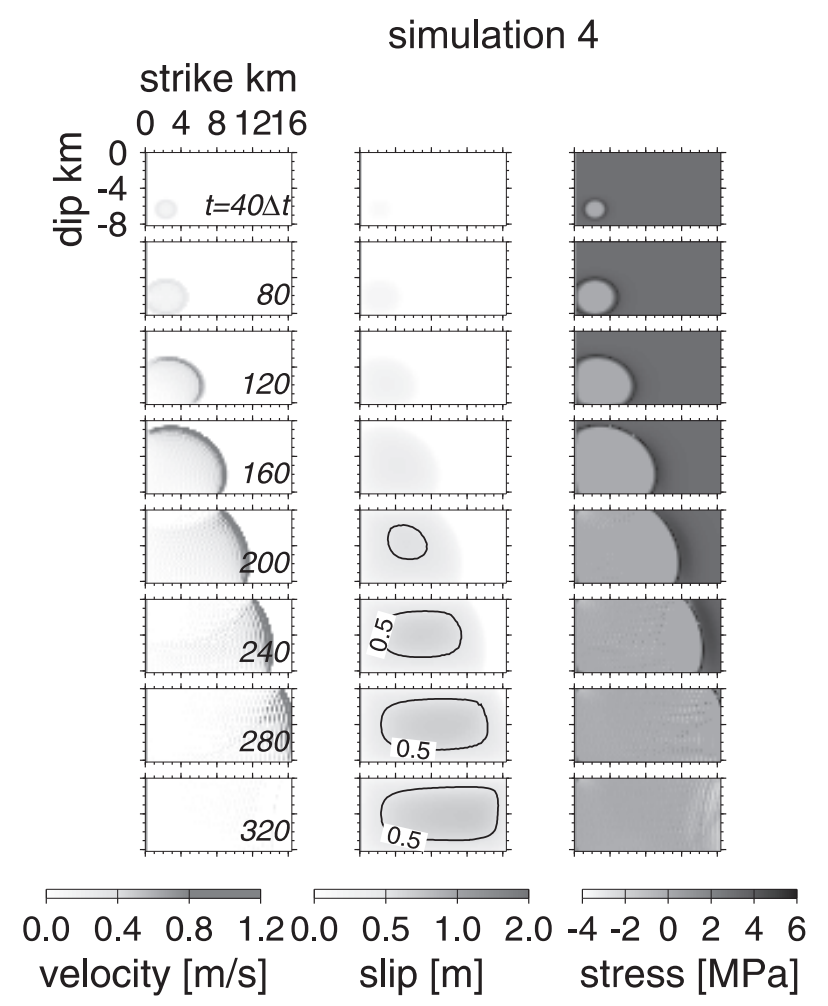

Figure 8: Snapshots of rupture propagation simulated with BIEM (Simulation 4). 


\section{List of Tables}

1 List of model parameters used in previous and current simulations. From left to right, (1) earthquake, (2) magnitude, (3) number of scenarios shown, (4) grid size in the BIEM, (5) time step in the BIEM, (6) shear-wave velocity in the BIEM, (7) numerical method for calculating seismic wave propagation after the BIEM simulation results, (8) displayed frequency range in near-field ground

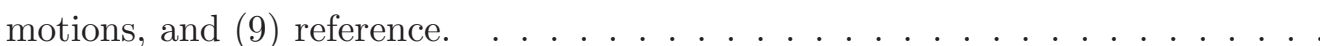

2 Simulation setting tested in this study. Fault length (L), width (W), strike $(\phi)$, dip $(\delta)$, rake $(\lambda)$, and the obtained moment magnitude $\left(M_{w}\right)$. Depth to the upper edge of the faults is $1 \mathrm{~km}$. See also Figure 1. . . . . . . . . . . . . 26

3 Crustal structure model used in the FDM simulations. . . . . . . . . . . . 27

4 Strong-motion parameters investigated and the empirical equations used for their prediction. . . . . . . . . . . . . . . . . . . 28

5 Computed means $(\mu)$ and standard deviations $(\sigma)$ of the residuals for the investigated parameters and the standard deviations estimated using observed data (from the selected ground motion estimation equations) $\left(\sigma_{\mathrm{emp}}\right) \ldots \ldots \ldots$

6 Computed correlation coefficients between strong-motion parameters computed from the simulations $($ horizontal $) \ldots \ldots \ldots \ldots \ldots$

$7 \quad$ Computed correlation coefficients between strong-motion parameters computed from the data of Ambraseys et al. [2005a] (horizontal) . . . . . . . . . . . . . 31

8 Model parameters in the BIEM simulations. . . . . . . . . . . . . . . 32 
Table 1: List of model parameters used in previous and current simulations. From left to right, (1) earthquake, (2) magnitude, (3) number of scenarios shown, (4) grid size in the BIEM, (5) time step in the BIEM, (6) shear-wave velocity in the BIEM, (7) numerical method for calculating seismic wave propagation after the BIEM simulation results, (8) displayed frequency range in near-field ground motions, and (9) reference.

\begin{tabular}{lccrrrrrl}
\hline Earthquake & $M_{w}$ & No. & $\begin{array}{r}\Delta s \\
(\mathrm{~m})\end{array}$ & $\begin{array}{r}\Delta t \\
(\mathrm{~s})\end{array}$ & $\begin{array}{r}V_{s} \\
(\mathrm{~km} / \mathrm{s})\end{array}$ & Method & $\begin{array}{r}\text { Freq. } \\
(\mathrm{Hz})\end{array}$ & Reference \\
\hline Landers & 7.2 & 4 & 750 & 0.060 & 3.52 & DWM & $0.05-0.3$ & $\begin{array}{l}\text { Aochi and } \\
\text { Fukuyama [2002], } \\
\text { Aochi et al. [2003] }\end{array}$ \\
Izmit & 7.6 & 5 & 1000 & 0.083 & 3.54 & FDM & $0.07-1$ & $\begin{array}{l}\text { Aochi and } \\
\text { Madariaga [2003] }\end{array}$ \\
Northridge & 6.7 & 9 & 400 & 0.032 & 3.64 & FDM & $<1$ & $\begin{array}{l}\text { Aochi and Olsen } \\
{[2004]}\end{array}$ \\
& $5.9-6.5$ & 7 & 256 & 0.021 & 3.46 & FDM & full range & this study \\
\hline
\end{tabular}


Table 2: Simulation setting tested in this study. Fault length $(\mathrm{L})$, width $(\mathrm{W})$, strike $(\phi)$, dip $(\delta)$, rake $(\lambda)$, and the obtained moment magnitude $\left(M_{w}\right)$. Depth to the upper edge of the faults is $1 \mathrm{~km}$. See also Figure 1.

\begin{tabular}{lrrrrrr}
\hline No. & $\mathrm{L}(\mathrm{km})$ & $\mathrm{W}(\mathrm{km})$ & $\phi\left(^{\circ}\right)$ & $\delta\left(^{\circ}\right)$ & $\lambda\left(^{\circ}\right)$ & $M_{w}$ \\
\hline 1 & 8.192 & 8.192 & 20 & 90 & 180 & 5.9 \\
2 & 8.192 & 8.192 & 45 & 45 & 90 & 5.9 \\
3 & 8.192 & 8.192 & 75 & 25 & 90 & 5.9 \\
4 & 16.384 & 8.192 & 20 & 90 & 180 & 6.2 \\
5 & 16.384 & 8.192 & 45 & 45 & 90 & 6.1 \\
6 & 16.384 & 8.192 & 75 & 25 & 90 & 6.1 \\
7 & 32.768 & 12.288 & 30 & 90 & 180 & 6.5 \\
\hline
\end{tabular}


Table 3: Crustal structure model used in the FDM simulations.

\begin{tabular}{cccc}
\hline Depth $(\mathrm{km})$ & $V_{p}(\mathrm{~m} / \mathrm{s})$ & $V_{s}(\mathrm{~m} / \mathrm{s})$ & $\mathrm{Q}$ \\
\hline 0 & 4000 & 2000 & 60 \\
1 & 6000 & 3264 & 300 \\
\hline
\end{tabular}


Table 4: Strong-motion parameters investigated and the empirical equations used for their prediction.

\begin{tabular}{|c|c|c|c|}
\hline Parameter & Distance metric & Components & Notes \\
\hline PGA & $\begin{array}{l}\text { Ambraseys et al. } d_{f} \\
{[2005 \mathrm{a}, \mathrm{b}]}\end{array}$ & $\mathrm{L}, \mathrm{V}$ & \\
\hline $\mathrm{PGV}$ & $\begin{array}{l}\text { Campbell }\left[1997, d_{s}\right. \\
2000,2001]\end{array}$ & $\mathrm{M}, \mathrm{V}$ & $\begin{array}{l}\text { Since the faults considered } \\
\text { here are at depths of } 1 \mathrm{~km}, d_{s} \\
\text { equals } d_{r} \text {. }\end{array}$ \\
\hline$\overline{\mathrm{SA}}$ & $\begin{array}{l}\text { Ambraseys et al. } d_{f} \\
{[2005 \mathrm{a}, \mathrm{b}]}\end{array}$ & $\mathrm{L}, \mathrm{V}$ & $\begin{array}{l}\text { For natural periods } 0.1,0.2 \text {, } \\
0.5,1.0 \text { and } 2.0 \mathrm{~s} \text { and ratio of } \\
\text { critical damping of } 5 \% \text {. }\end{array}$ \\
\hline$\overline{\mathrm{AI}}$ & $\begin{array}{l}\begin{array}{l}\text { Travasarou et al. } d_{r} \\
{[2003]}\end{array} \\
\end{array}$ & $\bar{M}$ & \\
\hline RSD & $\begin{array}{l}\text { Abrahamson and } d_{r} \\
\text { Silva [1996] }\end{array}$ & $\mathrm{M}, \mathrm{V}$ & \\
\hline
\end{tabular}


Table 5: Computed means $(\mu)$ and standard deviations $(\sigma)$ of the residuals for the investigated parameters and the standard deviations estimated using observed data (from the selected ground motion estimation equations) $\left(\sigma_{\mathrm{emp}}\right)$.

\begin{tabular}{lrrrrrr}
\hline & \multicolumn{3}{c}{ Horizontal } & \multicolumn{3}{c}{ Vertical } \\
Parameter & $\mu$ & $\sigma$ & $\sigma_{\text {emp }}$ & $\mu$ & $\sigma$ & $\sigma_{\text {emp }}$ \\
\hline PGA & 0.62 & 0.35 & $0.26-0.30$ & 0.56 & 0.32 & 0.28 \\
PGV & 0.41 & 0.23 & $0.17-0.24$ & 0.23 & 0.32 & $0.22-0.27$ \\
SA(0.1 s) & 0.67 & 0.39 & $0.27-0.32$ & 0.82 & 0.38 & 0.31 \\
SA(0.2 s) & 0.71 & 0.48 & $0.28-0.33$ & 0.76 & 0.29 & $0.26-0.29$ \\
SA(0.5 s) & 0.84 & 0.38 & $0.30-0.35$ & 0.69 & 0.35 & 0.30 \\
SA(1.0 s) & 0.71 & 0.26 & 0.33 & 0.45 & 0.45 & 0.30 \\
SA(2.0 s) & 0.41 & 0.24 & 0.31 & 0.39 & 0.42 & 0.32 \\
AI & 1.13 & 0.71 & $0.46-0.53$ & - & - & - \\
RSD & -0.17 & 0.14 & 0.21 & -0.23 & 0.20 & 0.20 \\
\hline
\end{tabular}


Table 6: Computed correlation coefficients between strong-motion parameters computed from the simulations (horizontal).

\begin{tabular}{lrrrrrrrrr}
\hline Parameter & PGA & PGV & SA(0.1 s) & SA(0.2 s) & SA(0.5 s) & SA(1.0 s) & SA(2.0 s $)$ & AI & RSD \\
\hline PGA & 1.00 & 0.92 & 0.95 & 0.88 & 0.82 & 0.72 & 0.71 & 0.86 & -0.09 \\
PGV & 0.92 & 1.00 & 0.85 & 0.87 & 0.86 & 0.89 & 0.85 & 0.76 & -0.14 \\
SA(0.1 s) & 0.95 & 0.85 & 1.00 & 0.79 & 0.76 & 0.70 & 0.65 & 0.84 & -0.09 \\
SA $(0.2 \mathrm{~s})$ & 0.88 & 0.87 & 0.79 & 1.00 & 0.90 & 0.67 & 0.62 & 0.77 & 0.09 \\
SA $(0.5 \mathrm{~s})$ & 0.82 & 0.86 & 0.76 & 0.90 & 1.00 & 0.67 & 0.60 & 0.70 & 0.13 \\
SA(1.0 s) & 0.75 & 0.89 & 0.70 & 0.67 & 0.67 & 1.00 & 0.90 & 0.53 & -0.30 \\
SA(2.0 s) & 0.71 & 0.85 & 0.65 & 0.62 & 0.60 & 0.90 & 1.000 & 0.53 & -0.32 \\
AI & 0.86 & 0.76 & 0.84 & 0.77 & 0.70 & 0.53 & 0.53 & 1.00 & 0.05 \\
RSD & -0.09 & -0.14 & -0.09 & 0.09 & 0.13 & -0.30 & -0.32 & 0.05 & 1.00 \\
\hline
\end{tabular}


Table 7: Computed correlation coefficients between strong-motion parameters computed from the data of Ambraseys et al. [2005a] (horizontal).

\begin{tabular}{|c|c|c|c|c|c|c|c|c|c|}
\hline Parameter & PGA & PGV & $\overline{\mathrm{SA}(0.1 \mathrm{~s})}$ & $\mathrm{SA}(0.2 \mathrm{~s})$ & $\mathrm{SA}(0.5 \mathrm{~s})$ & $\mathrm{SA}(1.0 \mathrm{~s})$ & $\mathrm{SA}(2.0 \mathrm{~s})$ & $\overline{\mathrm{AI}}$ & RSD \\
\hline PGA & 1.00 & 0.84 & 0.93 & 0.93 & 0.83 & 0.71 & 0.63 & 0.78 & -0.26 \\
\hline PGV & 0.84 & 1.00 & 0.73 & 0.79 & 0.90 & 0.92 & 0.90 & 0.73 & -0.04 \\
\hline $\mathrm{SA}(0.1 \mathrm{~s})$ & 0.93 & 0.73 & 1.00 & 0.86 & 0.68 & 0.57 & 0.54 & 0.74 & -0.29 \\
\hline $\mathrm{SA}(0.2 \mathrm{~s})$ & 0.93 & 0.79 & 0.86 & 1.00 & 0.77 & 0.64 & 0.57 & 0.80 & -0.23 \\
\hline $\mathrm{SA}(0$ & 0.83 & 0.90 & 0.68 & 0.77 & 1.00 & 0.85 & 0.74 & 0.73 & -0.10 \\
\hline $\mathrm{SA}(1$. & 0.71 & 0.92 & 0.57 & 0.64 & 0.85 & 1.00 & 0.87 & 0.64 & 0.04 \\
\hline $\mathrm{SA}(2.0 \mathrm{~s})$ & 0.63 & 0.90 & 0.54 & 0.57 & 0.74 & 0.87 & 1.00 & 0.60 & 0.11 \\
\hline AI & 0.78 & 0.73 & 0.74 & 0.80 & 0.73 & 0.64 & 0.60 & 1.00 & -0.04 \\
\hline RSD & -0.26 & -0.04 & -0.29 & -0.23 & -0.10 & 0.04 & 0.11 & -0.04 & 1.00 \\
\hline
\end{tabular}


Table 8: Model parameters in the BIEM simulations.

\begin{tabular}{lr}
\hline Parameter & Value \\
\hline P-wave velocity $\left(V_{p}\right)$ & $6000 \mathrm{~m} / \mathrm{s}$ \\
medium density $(\rho)$ & $2700 \mathrm{~kg} / \mathrm{m}^{3}$ \\
rigidity $(\mu)$ & $32.4 \mathrm{GPa}$ \\
\hline grid size $(\Delta s)$ & $256 \mathrm{~m}(512 \mathrm{~m}$ for simulation No.7) \\
time step $(\Delta t)$ & $0.043 \mathrm{~s}(0.085 \mathrm{~s}$ for simulation No.7) \\
\hline initial shear stress $\left(\tau_{0}\right)$ & $3 \mathrm{MPa}$ \\
yielding stress $\left(\tau_{p}\right)$ & $5 \mathrm{MPa}$ \\
residual stress $\left(\tau_{r}\right)$ & $0 \mathrm{MPa}$ \\
critical slip displacement $\left(D_{c}\right)$ & $12.5 \mathrm{~cm}(25 \mathrm{~cm}$ for simulation No.7) \\
\hline
\end{tabular}

